\title{
The Roles of Potassium Currents in Drosophila Flight Muscles
}

\author{
Thomas Elkins ${ }^{1, a}$ and Barry Ganetzky ${ }^{2}$ \\ 'Department of Zoology, and 'Laboratory of Genetics, University of Wisconsin, Madison, Wisconsin 53706
}

The roles of different $K+$ currents in regulating the generation and waveform of action potentials in Drosophila dorsal longitudinal flight muscles (DLMs) were examined in currentclamp experiments. In response to depolarizing current, DLMs displayed an initial transient rectification of the electronic potential lasting for up to hundreds of milliseconds. This delay in excitation was followed by oscillations or graded spikes that finally gave way to sharply rising spikes. Previous voltage-clamp studies of DLMs have revealed an inward $\mathrm{Ca}^{2+}$ current and at least three $K^{+}$currents: $I_{A}$ and $I_{K}$, which are voltage-dependent, and $I_{c}$, which is $\mathrm{Ca}^{2+}$ dependent. $I_{A}$ and $I_{C}$ are early inactivating currents, while $I_{K}$ is a slow, noninactivating current. In mature adults, selective elimination of $I_{A}$ either with Shaker (Sh) mutations or with 4-aminopyridine (4-AP), had no effect on spike duration or on the delay in excitation. In contrast, when $I_{c}$ was specifically eliminated with the slowpoke (s/o) mutation, there was no delay before excitation, the amplitude of the spikes was significantly increased, and the spike duration was increased by 10 -fold. Similar results were obtained by reducing $l_{c}$ in normal muscle by intracellular injections of EGTA or by use of low $\mathrm{Ca}^{2+}$ saline. Furthermore, DLM spikes evoked in slo by stimulation of the motorneuron were also broadened, suggesting that $I_{c}$ functions in a similar manner during normal flight as in current-clamped muscles. Elimination of $I_{\mathrm{K}}$ along with $I_{\mathrm{A}}$ and $I_{\mathrm{C}}$ in saline containing tetraethylammonium or $\mathrm{Ba}^{2+}$ resulted in further prolongation of the DLM spike. In $\mathrm{Ba}^{2+}$ saline, there was an additional increase in spike amplitude as well. We conclude that in mature adults, $I_{C}$, rather than $I_{A}$, plays the major role in repolarization of DLM spikes and in the delay before excitation. In the absence of $I_{c}$, spike duration and amplitude is limited by $I_{\mathrm{K}}$ and $\mathrm{Ca}^{2+}$ inactivation. We also present evidence showing that prior to the full development of $I_{C}$ in the young adult, $I_{A}$ is responsible for early spike repolarization.

The diversity in electrical properties among excitable cells is determined in large part by the array of ion channel types present in the membrane of different cells. To elucidate the underlying basis of the signaling properties of particular excitable cells, it

\footnotetext{
Received Oct. 2, 1986; revised July 27, 1987; accepted Aug. 13, 1987.

This work was supported by NIH Grant NS15390 and Research Career Development Award NS00719 to B. G. and NIH Grant NSGM07133 to the Laboratory of Genetics. We thank our colleagues, especially G. Robertson and C.-F Wu, for helpful discussions and comments on the manuscript. We also thank $\mathrm{L}$ M. Passano and the Department of Zoology for the use of equipment. Paper no. 2901 from the Laboratory of Genetics, University of Wisconsin, Madison.

Correspondence should be addressed to Barry Ganetzky at the above address.

a Present address: Department of Biological Sciences, Stanford University, Stanford, CA 94305.

Copyright (C) 1988 Society for Neuroscience $0270-6474 / 88 / 020428-07 \$ 02.00 / 0$
}

is necessary to identify the types of ion channels present and to assess the functional role(s) of each channel type (e.g., Thompson, 1977; Miller, 1987). The availability of toxins and other pharmacological agents that specifically block certain channel types have been extremely useful in studies to obtain this kind of information. In Drosophila melanogaster this approach can be further extended by the use of mutations that specifically disrupt or eliminate the function of particular channels (for reviews, see Ganetzky and Wu, 1986; Salkoff and Tanouye, 1986; Tanouye et al., 1986).

The flight muscles of Drosophila adults and the body wall muscles of larvae are favorable for studies of this kind because the various ion currents present in these cells have been studied by voltage-clamp experiments and because several of these currents can be individually blocked by different mutations (Salkoff and Wyman, 1981, 1983; Salkoff, 1983a; Wu et al., 1983; Wu and Haugland, 1985). In the dorsal longitudinal flight muscles (DLMs) of mature adult flies, a single inward current and at least 3 distinct outward currents have been described (Salkoff and Wyman, 1983). The inward current, which gives rise to the muscle action potential, is carried by $\mathrm{Ca}^{2+}$. The outward currents are carried by $\mathrm{K}^{+}$and comprise 2 classes: voltage-dependent $\mathrm{K}^{+}$channels $\left(I_{\mathrm{A}}\right.$ and $\left.I_{\mathrm{K}}\right)$ and $\mathrm{Ca}^{+}$-dependent $\mathrm{K}^{+}$channels $\left(I_{\mathrm{C}}\right) . I_{\mathrm{A}}$ and $I_{\mathrm{C}}$ are early inactivating currents, while $I_{\mathrm{K}}$ is a slow noninactivating current. Recently, an additional slow, $\mathrm{Ca}^{2+}$ dependent $\mathrm{K}^{+}$current has been described in pupal DLMs (Wei and Salkoff, 1986). These $\mathrm{K}^{+}$currents are similar to those that have been identified and studied in other systems.

In axons of squid and other organisms, $I_{\mathrm{K}}$ has been shown to play the primary role in repolarization of action potentials (Hodgkin and Huxley, 1952). A fast, inactivating $\mathrm{Ca}^{2+}$-dependent $\mathrm{K}^{+}$current, similar to $I_{\mathrm{C}}$, has been shown to be involved in repolarizing action potentials in the somata of some vertebrate neurons (Adams et al., 1982; MacDermott and Weight, 1982; Rogawski et al., 1985). In various molluscan neurons, and in some vertebrate neurons as well, $I_{\mathrm{A}}$ modulates the voltage dependence of spike frequency and is also responsible for the delay of excitation in response to steady depolarization (Conner and Stevens, 1971 a, b; Byrne, 1980; Getting, 1983; Shimahara, 1983; Segal et al., 1984).

In this paper, we describe the respective roles of the different $\mathrm{K}^{+}$currents in regulating the generation and waveform of action potentials in the Drosophila DLMs. In particular, we examined the consequences of selectively eliminating various $\mathrm{K}^{+}$currents on action potential repolarization and delayed excitation. These experiments were initiated with the isolation of a mutation, named slowpoke (slo), that specifically eliminates $I_{\mathrm{C}}$ (Elkins et al., 1984, 1986). We also took advantage of Shaker $(S h) \mathrm{mu}-$ tations that specifically eliminate $I_{\mathrm{A}}$ (Salkoff and Wyman, 1981; Salkoff 1983a; Wu and Haugland, 1985). Conclusions about the 

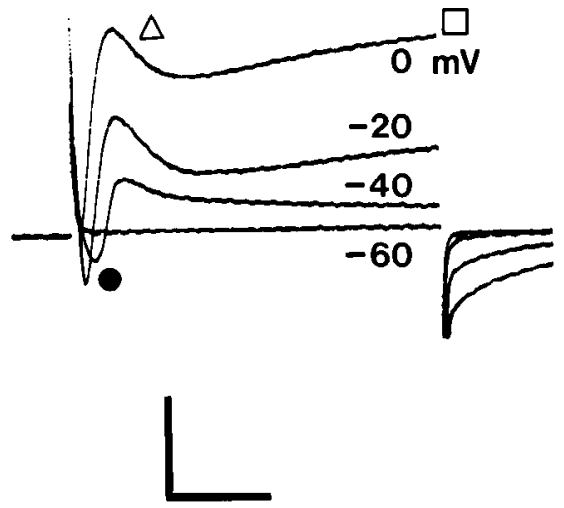

b
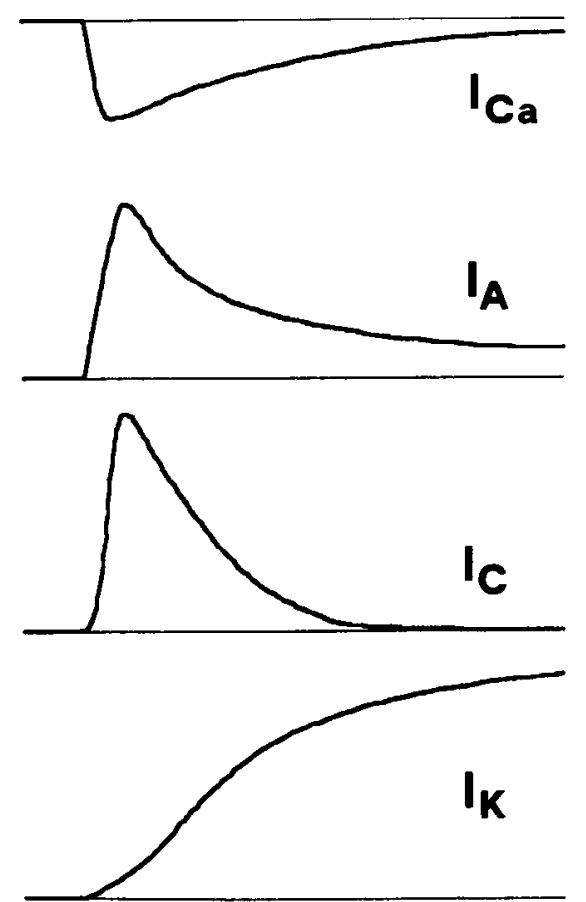

Figure 1. a, Membranc currents in dorsal longitudinal flight muscles (DLMs). Current responses (lower traces) to voltage-clamp steps (upper traces) in a normal DLM fiber. The membrane was held at $-80 \mathrm{mV}$ and stepped to $-60,-40,-20$, and $0 \mathrm{mV}$ for $140 \mathrm{msec}$, as indicated. The pulse to $-60 \mathrm{mV}$ activates only passive leakage current. At $-40 \mathrm{mV}$ an inward (downward) $\mathrm{Ca}^{2+}$ current (closed circle) is followed by an inactivating outward current (triangle). This outward current is separable into 2 components, the voltage-dependent $I_{\mathrm{A}}$ and the $\mathrm{Ca}^{2+}$-dependent $I_{C}$ (see text for details). At -20 $\mathrm{mV}$, a delayed outward current, $I_{\mathrm{K}}$, is evident (square). $b$, Idealized diagram of the individual ion currents, showing their approximate amplitudes and time courses in response to the voltage step to $0 \mathrm{mV}$ above. Calibration: $0.2 \mathrm{~V}, 400$ $\mathrm{nA}, 40 \mathrm{msec}$. roles of these currents based on the analysis of mutants were confirmed and extended by ion-substitution experiments and by the use of specific blocking agents. From these experiments, it appears that $I_{\mathrm{C}}$ plays the major role both in action potential repolarization and delayed excitation in these cells. The possible functions of the other $\mathrm{K}^{+}$currents are also discussed.

\section{Materials and Methods}

Mutants used in these studies include $S h^{\mathrm{KS} 133}$ (Jan et al., 1977) and slo (Elkins et al., 1986). Previous voltage-clamp experiments have demonstrated that $S h^{\mathrm{KS} 133}$ causes the specific elimination of $I_{\mathrm{A}}$ (Salkoff and Wyman, 1981; Salkoff, 1983a; Wu and Iaugland, 1985), while slo specifically abolishes $I_{\mathrm{C}}$ (Elkins et al., 1986). Neither mutation causes a detectable alteration in any other current in the DLMs. Control flies were from the Canton-S wild-type strain.

Adult female flies 1-2 d posteclosion were used for all experiments except where noted otherwise. To observe the responses of DLMs to motorneuron activity, a $20 \mathrm{mV}, 200 \mu \mathrm{sec}$ pulse was applied to the cervical connective with a pair of insulated tungsten electrodes that were electrically isolated from ground, thus stimulating the giant fiber pathway that includes the DLM motorneurons (King and Wyman, 1980). A tungsten electrode inserted through the abdomen measured a reference potential, while the fly was immobilized in air by gluing it to a pin with cyanoacrylate adhesive.

For current- and voltage-clamp experiments, the dorsal thoracic cuticle was removed with tungsten scalpels and the DLMs were exposed to saline. The thoracic and abdominal spiracles were aerated as reported by Ikeda and Kaplan (1974). The preparation was cooled on a Peltier plate to $18^{\circ} \mathrm{C}$ for current-clamp and to $4^{\circ} \mathrm{C}$ for voltage-clamp experiments. The saline was composed of 0.05 (low) or $1.8 \mathrm{~mm}$ (normal) $\mathrm{CaCl}_{2}, 8 \mathrm{~mm} \mathrm{MgCl}, 123 \mathrm{mM} \mathrm{NaCl}, 2 \mathrm{mM} \mathrm{KCl}, 35.5 \mathrm{~mm}$ sucrose and buffered at $\mathrm{pH} 7.1$ with $5 \mathrm{~mm}$ HEPES.

All experiments were performed on DLM $45 \mathrm{a}$ or $\mathrm{b}$ according to the nomenclature of Miller (1965). Only cells with a resting potential of $-70 \mathrm{mV}$ or greater were used. Glass microelectrodes were filled with $2.5 \mathrm{M} \mathrm{KCl}$ and beveled using a silicon carbide grit (Kripke and Ogden, 1974) to 5-10 $\mathrm{M} \Omega$ for easier penetration and drug injection. Each experiment was repeated on 3-15 individuals.

Two-microelectrode current-clamp and voltage-clamp experiments were performed according to standard methods with a Dagan 5700 current/voltage clamp. Signals were photographed from a Tektronix storage oscilloscope.

For EGTA injection, a current-passing electrode was filled with 100 mM EGTA. Long DC pulses of $10 \mathrm{nA}$ current were applied for up to 2 min, producing an estimated EGTA transfer of $6 \times 10^{-12}$ moles. Active responses were then evoked by applying $120 \mathrm{msec}$ depolarizing pulses.

\section{Results}

Ion currents in the DLM membrane

In addition to the inward $\mathrm{Ca}^{2+}$ current, at least 3 outward $\mathrm{K}^{+}$ currents are present in the DLMs of normal flies (Salkoff and Wyman, 1983; Salkoff, 1983a). Voltage-clamp traces from a normal DLM, in which these currents are superimposed, are shown in Figure 1. During a voltage step to $-40 \mathrm{mV}$, the inward (downward) current is followed by 2 early, inactivating outward currents that superimpose, the $\mathrm{Ca}^{2+}$-dependent $I_{\mathrm{C}}$ and the voltage-dependent $I_{\mathrm{A}}$. At steps to -20 and $0 \mathrm{mV}$, these 2 outward currents are followed by $I_{\mathrm{K}}$, which does not inactivate during the current pulse.

\section{Delayed excitation and graded spikes}

When a normal DLM was depolarized with a steady current, it did not immediately respond with an all-or-none action potential (Salkoff and Wyman, 1980). Instead, voltage became partially rectified, reaching a plateau at about $-50 \mathrm{mV}$. After charging the membrane for tens to hundreds of milliseconds, oscillations or graded spikes of increasing amplitude were often seen that gave way to sharply rising spikes (Fig. 2a). As the magnitude and rate of depolarization were increased, the extent of the delay before spiking decreased (Salkoff and Wyman, 1980). At peak amplitude, the spikes did not overshoot $0 \mathrm{mV}$ but reached membrane potentials of about $-10 \mathrm{mV}$.

To investigate the roles of $I_{\mathrm{A}}$ and $I_{\mathrm{C}}$ in the delay of excitation, we examined the response to steady depolarization under conditions where each of these currents was selectively blocked. 
Figure 2. Membrane potential changes produced by constant depolarizing current pulses in normal and mutant DLMs. In this figure and those that follow, the traces shown are representative of all individuals examined for a given genotype and expcrimental condition. The number of cells examined in each case is shown. $a$, Normal (Canton S), $n=50 . b$, Normal in saline containing $5 \mathrm{~mm}$ 4-AP, $n=5$. c, Shaker mutant $\left(S h^{\mathrm{ks} 133}\right), n=10 . d$, Slowpoke mutant (slo), $n=70$. $e$, slo in saline containing $5 \mathrm{~mm} 4-\mathrm{AP}, n=5 . f$, $S h^{\mathrm{Ks} 133}$; slo double mutant, $n=10$. Temperature for all current-clamp experiments: $18^{\circ} \mathrm{C}$. Calibration: $20 \mathrm{mV}, 100 \mathrm{nA}, 20 \mathrm{msec}$. a) normal

b) normal + 4-AP

c) $S h^{K S 133}$

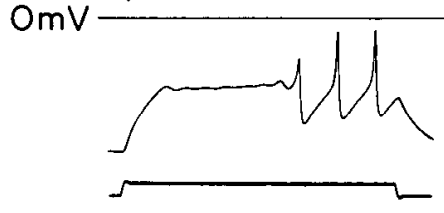

d) 510
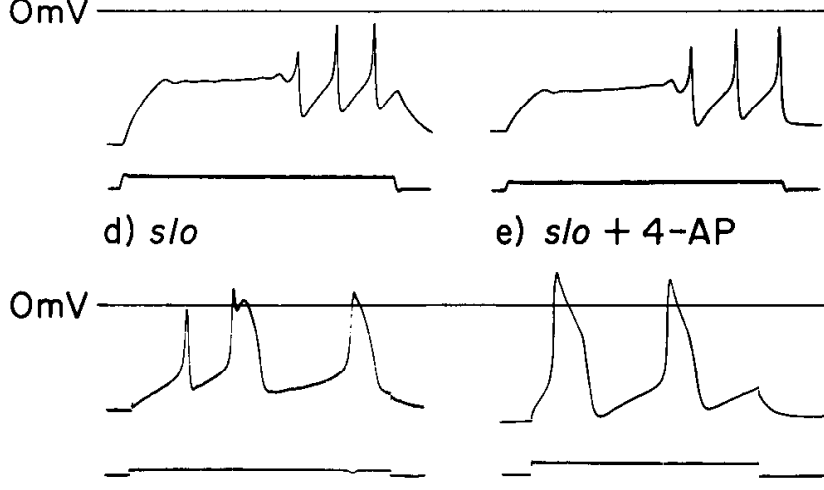

e) $5 / 0+4-A P$

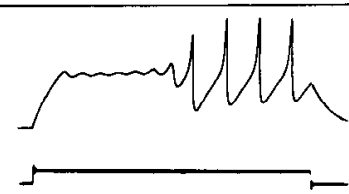

f) $S h^{K S / 33}$; $s / 0$

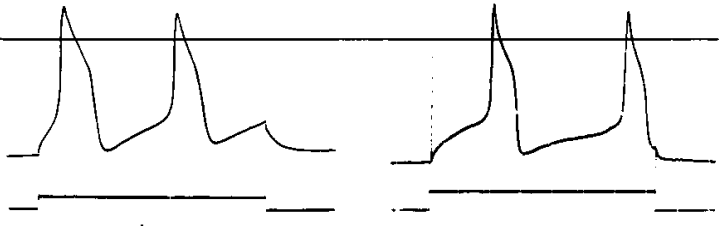

Although $I_{\mathrm{A}}$ is completely absent in the DLMs of $S h^{\mathrm{KS} 133}$ (Salkoff and Wyman, 1981), delayed excitation occurs as in normal flies (Fig. 2c). Similarly, when normal flies are treated with 4-AP, which selectively eliminates $I_{\mathrm{A}}$ (Salkoff, 1983a), there is no effect on delayed excitation (Fig. $2 b$ ). These results indicate that the DLMs, unlike molluscan neurons, do not require $I_{\mathrm{A}}$ for delayed excitation.

The result was very different when similar experiments were performed on $s l o$, a mutation that has been shown to eliminate $I_{C}$ completely and specifically (Elkins et al., 1986). In the DLMs of this mutant, a depolarizing pulse caused the cell to reach firing threshold without any delay (Fig. 2d). Since a specific block in $I_{C}$ results in the loss of delayed excitation, it is evident that this current normally plays the major role in producing delayed excitation.

The response to steady depolarization in slo DLMs is unusual in another respect. The first spike evoked by depolarization rapidly repolarizes and is followed by spikes whose duration is markedly prolonged (Fig. $2 d$ ). This raises the question of how the spike waveform is normally shaped by the various $\mathrm{K}^{+}$currents.

\section{Roles of $\mathrm{I}_{A}$ and $\mathrm{I}_{C}$ in spike repolarization}

Under current-clamp conditions, a train of action potentials is evoked in DLMs of normal flies that repolarize after $1.9 \pm 0.2$ msec (measured at $1 / 2$ maximal amplitude) (Fig. $2 a$ ). These spikes do not overshoot. The action potentials evoked in $S h^{\text {KS133 }}$ DLMs or in normal DLMs treated with 4-AP did not differ from normal in amplitude or duration (Fig. 2, $b, c$; cf. Salkoff, 1985). In contrast, following the first spike of a train, the action potentials evoked in DLMs of slo flies remained depolarized for $19 \pm 1$ msec and were invariably overshooting, reaching membrane potentials around $+10 \mathrm{mV}$ (Fig. $2 d$ ). These results suggest that during a train of action potentials evoked under current-clamp conditions, $I_{\mathrm{C}}$ but not $I_{\mathrm{A}}$ is normally required for early spike repolarization and for limiting the spike amplitude (Elkins et al., 1984; Salkoff, 1985).

However, even in slo DLMs, the first spike in a train usually repolarized with approximately normal kinetics and did not overshoot, suggesting that repolarization of the first spike in a train occurs by a different mechanism from that of subsequent spikes. To investigate further the mechanism involved in repolarization of the first spike in a train, we assayed the response in flics lacking both $I_{\mathrm{A}}$ and $I_{\mathrm{C}}$. Flies lacking both currents were produced either by treating slo flies with $5 \mathrm{~mm} 4-\mathrm{AP}$ or by constructing $S h^{\mathrm{KS} 133}$; slo double mutants. In both of these experiments, the first spike evoked under current-clamp conditions became as prolonged as the following spikes and were ovcrshooting as wcll (Fig. 2,e,f). Wc conclude that the prompt repolarization of the first spike in a series is normally accomplished by $I_{\Lambda}$. Elimination of both $I_{\Lambda}$ and $I_{C}$ then results in uniformly prolonged spikes of increased amplitude.

If $I_{\mathrm{A}}$ is sufficient to bring about the early repolarization of the first spike in a series, why is it apparently unable to do the same thing for subsequent spikes? One possible explanation is the inactivation of $I_{\mathrm{A}}$ during prolonged depolarization (Salkuff, 1985). Measurements of the exponential time constant for recovery from inactivation of $I_{\mathrm{A}}$ in voltage-clamp experiments (Salkoff and Wyman, 1983) suggest that, at the membrane potentials reached between spikes in our experiments, $I_{\mathrm{A}}$ would not appreciably recover from inactivation.

To establish that the effect of slo on repolarization of the DLM spike could be attributed solely to the elimination of $I_{\mathrm{C}}$ rather than to some additional undetected defect in the mutant, we reduced $I_{C}$ experimentally in normal flies and examined the consequences on DLM spikes. In one series of experiments, DLMs were current-clamped after the extracellular $\mathrm{Ca}^{2+}$ was lowered from 1.8 to $0.05 \mathrm{mM}$. In voltage-clamp experiments it was found that this lowering of $\mathrm{Ca}^{2+}$ resulted in a 4-fold reduction in the amplitude of $I_{C}$ (not shown). Under these conditions, long-duration spikes, albeit of reduced amplitude, were readily evoked by a $120 \mathrm{msec}$ depolarizing pulse and the delay before excitation was shortened relative to normal (Fig. $3 a$ ).

A second series of experiments involved the injection of EGTA into normal DLMs to chelate the intracellular free $\mathrm{Ca}^{2+}$ that is required to activate $I_{\mathrm{C}}$. After injection, depolarizing pulses evoked one to several spikes of short duration followed by a series of long-lasting spikes (Fig. $3 b$ ). The effect of EGTA on spikes was temporary. Within $10 \mathrm{sec}$ after injection, the spikes returned to their normal duration of $2 \mathrm{msec}$. During the time that the spikes were prolonged, there was also a reduction in the delay before excitation (Fig. $3 b$ ). In contrast, in $s l o$, injection of EGTA into the DLMs did not result in any additional increase in spike duration (Fig. 3c). That the slo phenotype can be mimicked in normal DLMs by reducing $I_{C}$ in these cells whereas similar treatment has no effect on slo supports the conclusion that the altered DLM spikes in slo results specifically from the loss of $I_{\mathrm{C}}$. 


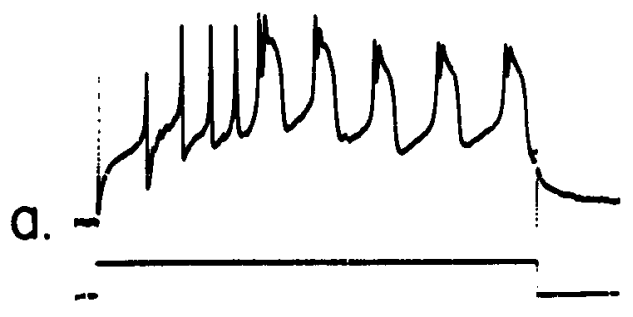

b.

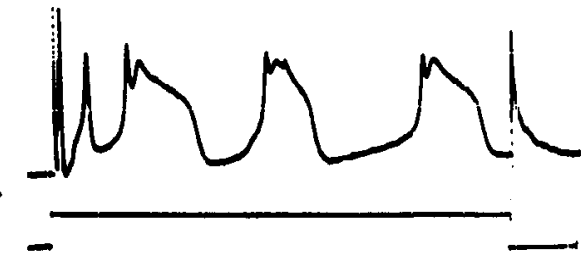

C.

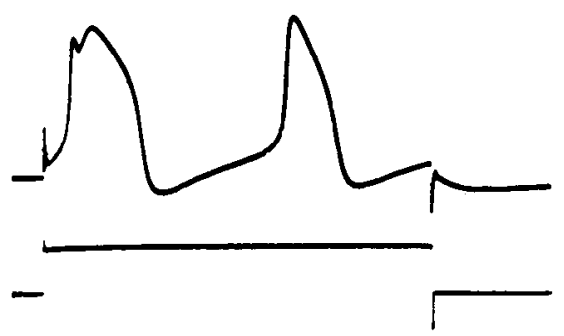

Figure 3. Membrane potential changes in DLMs produced by constant depolarizing current pulses in low $\mathrm{Ca}^{2+}$ or after injection of EGTA. $a$, Normal DLM in saline containing low $(0.05 \mathrm{mM}) \mathrm{Ca}^{2+}(n=5)$. $b$, Normal DLM following intracellular injection of EGTA. The voltage spikes at the start and end of the pulse probably result from clogging of the electrode tip by EGTA $(n=5)$. $c$, slo DLM following intracellular injection of EGTA $(n=7)$. The failure of the first spike to repolarize quickly in this particular cell is attributed to slight damage to the cell during injection leading to partial loss of resting potential and inactivation of $I_{\mathrm{A}}$. Calibration: $a, 20 \mathrm{mV}, 100 \mathrm{nA}, 50 \mathrm{msec} . b$ and $c, 20 \mathrm{mV}$, $100 \mathrm{nA}, 20 \mathrm{msec}$.
Role of $\mathrm{I}_{A}$ and $\mathrm{I}_{C}$ in young adults

The control of DLM spike repolarization appears to differ in mature adults compared with flies newly eclosed from the pupal case. It was observed that whereas DLM spikes in newly eclosed normal flies repolarize as quickly as they do in mature adults, the spikes in newly eclosed $S h^{\mathrm{KS} 133}$ adults are of longer duration (Salkoff, 1985 and Fig. 4). Furthermore, the DLM spikes in slo adults aged $1-2 \mathrm{hr}$ posteclosion are not prolonged but repolarize as quickly as in normal flies of the same agc (Fig. 4). Spike repolarization in newly eclosed $S h^{\mathrm{KS} 133}$; slo double mutants was no more abnormal than for $S h^{\mathrm{KS} 133}$ alone (Fig. 4). These results indicate that in newly eclosed adults, in contrast to mature adults, $I_{\mathrm{A}}$ does play an important role in repolarization of DLM spikes (cf. Salkoff, 1985), while $I_{\mathrm{C}}$ is unnecessary. In addition, the DLM responses in newly eclosed flies differ from those of mature adults in that the delay in excitation is not observed in normal flies (Fig. 4).

These results are consistent with the observation that $I_{\mathrm{C}}$ is not fully present in pupal muscles but appears only gradually in the DLM membrane over a period of hours following eclosion (Salkoff, 1985). Apparently, while $I_{\mathrm{A}}$ is necessary and sufficient to repolarize the DLM spikes in newly eclosed adults, $I_{\mathrm{C}}$ must develop fully before there is a delay in excitation.

\section{Role of $\mathrm{I}_{K}$ and $\mathrm{Ca}^{2+}$ inactivation in spike repolarization and refractory period}

No mutants are available that specifically eliminate $I_{\mathrm{K}}$ in DLMs. Nor is it possible pharmacologically to remove this current in DLMs without affecting other $\mathrm{K}^{+}$currents as well. Nonetheless, it is possible to infer the role of $I_{\mathrm{K}}$ in spike repolarization by comparing DLM responses under conditions where $I_{\mathrm{A}}, I_{\mathrm{C}}$, and $I_{\mathrm{K}}$ are all blocked with the responses obtained when only $I_{\mathrm{A}}$ and $I_{\mathrm{C}}$ are missing. In voltage-clamp experiments $100 \mathrm{mM}$ TEA was found to block all 3 outward currents completely, whereas the inward $\mathrm{Ca}^{2+}$ current remained intact (not shown). In the presence of $100 \mathrm{~mm}$ TEA under current-clamp conditions, normal

\section{a. normal b. $S h^{K S 133}$}

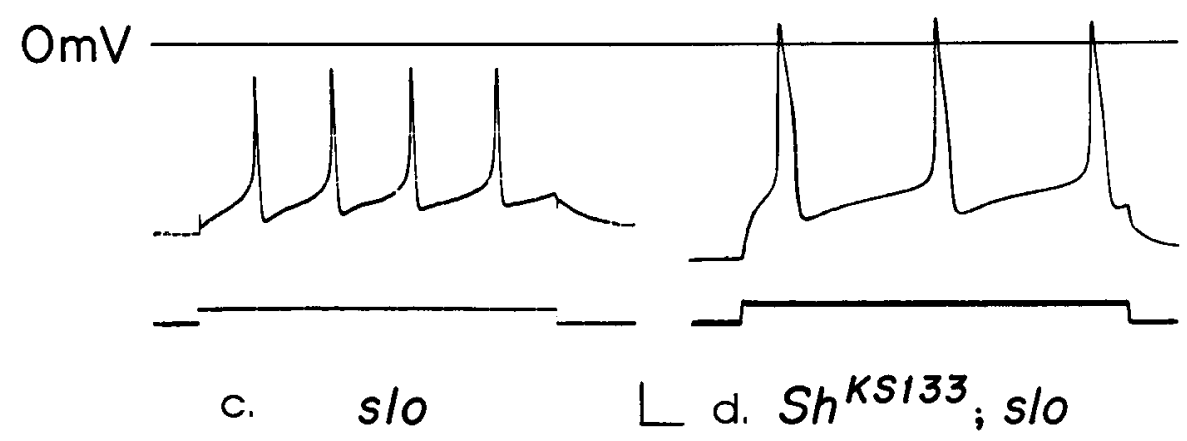

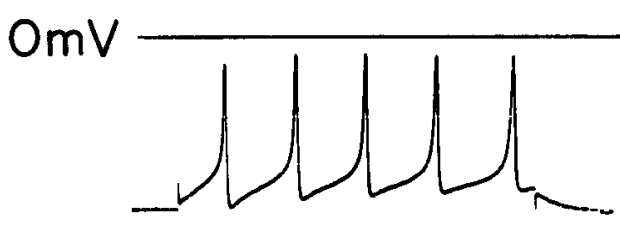

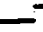

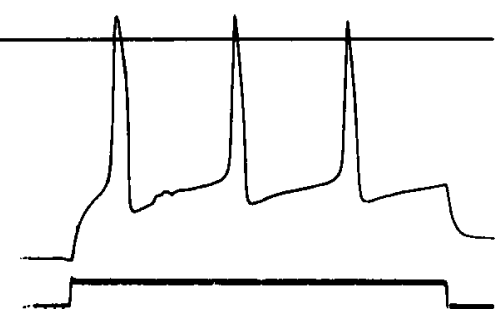

Figure 4. Membrane potential changes in DLMs of newly eclosed normal and mutant adults produced by constant depolarizing current pulses. Age of flies in each case is one hour posteclosion. $a$, Normal, $n=6 . b, S h^{\mathrm{kS} 133}, n=10 . c$, slo, $n=10 . d, S h^{\mathrm{KS} 133} ;$ slo double mutant $n=5$. Calibration: $20 \mathrm{mV}, 100 \mathrm{nA}, 20$ msec. 
Figure 5. Membrane potential changes in normal DLMs produced by constant depolarizing current pulses in the presence of $\mathrm{K}^{+}$-channel blockers. $a$, Normal in saline containing $100 \mathrm{~mm}$ TEA $(n=20)$. The responses from two consecutive current pulses spaced $1.5 \mathrm{sec}$ apart are superimposed. $b$, Normal in saline containing $0 \mathrm{mM} \mathrm{Ca}{ }^{2+}$ and 10 $\mathrm{mM} \mathrm{Ba}^{2+}(n=20)$. Calibration: $20 \mathrm{mV}$, $100 \mathrm{nA}, 0.1 \mathrm{sec}$ in $a$ and $0.5 \mathrm{sec}$ in $b$.

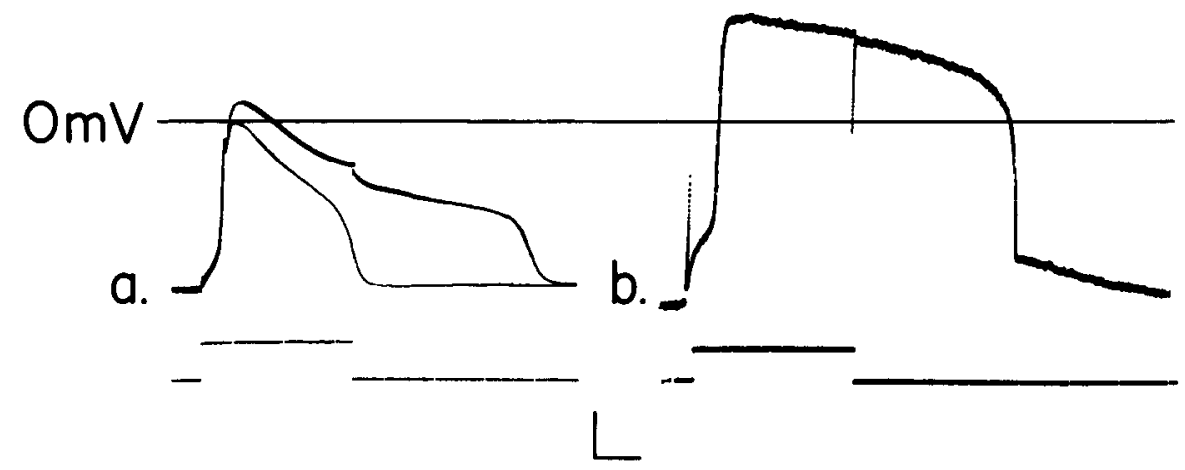

DLMs produced very long-lasting spikes up to $4 \mathrm{sec}$ in duration (Fig. 5a). The amplitude of these spikes was greater than normal but comparable to that previously observed in slo or $S h^{\mathrm{KS} 133}$; slo. If a second current pulse was applied soon after repolarization of the first response, the second response that was evoked usually had less than half the duration of the first (Fig. 5a). One possible reason for this result is that the prolonged $\mathrm{Ca}^{2+}$ influx during the first spike results in an increased level of $\mathrm{Ca}^{2+}$ current inactivation, which is capablc of tcrminating the sccond spikc.

In voltage-clamp experiments, $10 \mathrm{mM} \mathrm{Ba}^{2+}$ resembled TEA in its effects on blocking outward currents (not shown). $\mathrm{Ba}^{2+}$ was found to reduce $I_{\mathrm{K}}$ severely in DLMs, as it does in squid axon (Eaton and Brodwick, 1980), and blocked $I_{\mathrm{A}}$ almost completely as well. In addition, $\mathrm{Ba}^{2+}$ either blocked or failed to activate $I_{\mathrm{C}}$. However, in contrast to TEA-treated muscle fibers, $\mathrm{Ba}^{2+}$ also greatly reduced inactivation of the inward current. In saline containing $10 \mathrm{mM} \mathrm{Ba}^{2+}$ and $0 \mathrm{mM} \mathrm{Ca}^{2+}$, the DLM response evoked under current clamp remained depolarized for periods ranging from several seconds to more than a minute and reached membrane potentials of greater than $+30 \mathrm{mV}$ (Fig. $5 b$ ). Similar responses to these were observed with slo DLMs in the presence of $\mathrm{Ba}^{2+}$ (not shown).

These data suggest that when $I_{C}$ is absent, as in slo flies, repolarization of the DLM spike is eventually accomplished by $I_{\mathrm{K}}$. Consequently, blocking of $I_{\mathrm{K}}$ along with $I_{\mathrm{C}}$ and $I_{\mathrm{A}}$ results in spikes that can persist for several seconds or more.

\section{Repolarization of synaptically evoked spikes}

The prolonged DLM spikes observed in slo mutants were elicited under current-clamp conditions. It was thus of interest to ask whether loss of $I_{C}$ would have a similar effect under experimental conditions that more closely resembled normal flight.
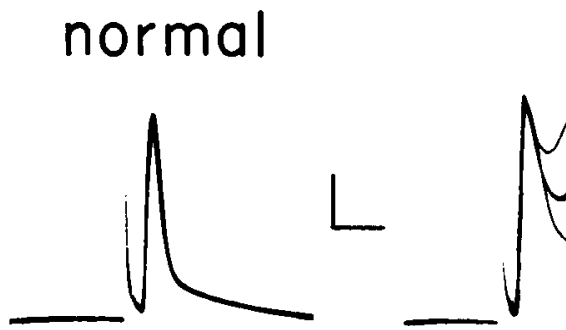

slo

Figure 6. Membrane potential changes produced in normal and slo DLMs in response to repetitive stimulation of the motorneuron. In each case, 5 consecutive responses are shown superimposed. The motorneuron was stimulated at a frequency of $5 \mathrm{~Hz}(n=100)$. Calibration: 20 $\mathrm{mV}, 20 \mathrm{msec}$.
During normal flight, the firing frequency of the DLMs is about $5 \mathrm{~Hz}$ (Harcombe and Wyman, 1978; Koenig and Ikeda, 1980). In Figure 6 we show the response of normal and slo DLMs to repetitive stimulation at a frequency of $5 \mathrm{~Hz}$. In normal flies, each spike repolarized within $2 \mathrm{msec}$ (Fig. 6a). In contrast, in slo flies the first spike repolarized with a normal time course, but subsequent spikes were about $20 \mathrm{msec}$ in duration (Fig. 6b). These results are the same as those observed in the currentclamp experiments. It therefore secms very likcly that $I_{\mathrm{C}}$ plays the major role in repolarization of DLM spikes during normal flight. This conclusion is consistent with our previous observation that slo mutants fly very poorly or not at all (Elkins et al., 1986).

\section{Discussion}

In these experiments we have used mutations in Drosophila in a manner similar to specific pharmacological agents to dissect the physiological roles for the different $\mathrm{K}^{+}$currents in flight muscles. Despite their similar amplitude and time course in voltage-clamp experiments, $I_{\mathrm{A}}$ and $I_{\mathrm{C}}$ apparently have very different functions in DLMs. In other systems, delayed excitation is dependent upon the function of $I_{\mathrm{A}}$ (Conner and Stevens, 1971a, b; Byrne, 1980; Getting, 1983; Shimahara, 1983; Segal et al., 1984). In Drosophila DLMs, however, elimination of $I_{\mathrm{A}}$ by $S h^{\mathrm{Ks} 133}$ has no detectable effect on delayed excitation. In contrast, specific elimination of $I_{\mathrm{C}}$ by slo results in the complete loss of delayed excitation. Similarly, repolarization of the DLM spikes is essentially normal in the absence of $I_{\mathrm{A}}$ but prolonged by a factor of 10 when $I_{\mathrm{C}}$ is blocked. In addition, the interspike interval is increased from 20 to $40 \mathrm{msec}$ in slo but is normal in $S h$. Thus, at least under current-clamp conditions, $I_{c}$ plays the major role in controlling these aspects of the electrical activity of DLMs.

Loss of $I_{C}$ probably alters DLM responses during flight in a manner similar to that observed in current-clamp experiments, consistent with the diminished flight ability of slo flies (Elkins et al., 1986). For example, we observed that DLM spikes evoked by endplate potentials in response to stimulation of the motorneuron at frequencies corresponding to that of normal flight were as prolonged as those observed under current-clamp conditions. It will be of interest to determine whether such prolonged DLM spikes also cause an alteration in the interspike interval during normal flight. It remains unclear whether the phenomenon of delayed excitation has a physiological role in the normal activity of DLMs. The endplate potential during normal flight is very large and fast rising. As a result, it does not produce the graded depolarization that causes delayed excitation as during current-clamp experiments but instead im- 
mediately activates a full-sized DLM spike (Boettinger, 1951). However, in muscles of some other arthropods, graded spiking can be observed in response both to current injection (Fatt and Katz, 1953) and normal synaptic excitation (Hoyle, 1967). Therefore, in organisms related to flies, there may be an important biological role for graded muscle spiking, and, as in Drosophila, the mechanism that produces these graded responses may also depend on the action of a $\mathrm{Ca}^{2+}$-dependent $\mathrm{K}^{+}$ current.

In newly eclosed flies, in contrast with those several hours older, $I_{\mathrm{A}}$ plays an important role in regulating the duration, amplitude, and frequency of DLM spikes. These functions are apparently taken over within a few hours after eclosion by $I_{C}$ (cf. Salkoff, 1985). Elimination of $I_{\mathrm{A}}$ in newly eclosed flies has effects on DLM activity similar to those caused by elimination of $I_{\mathrm{C}}$ in mature adults, including overshooting spikes, prolonged spike duration, and increased interspike interval. Thus, DLM responses are normal in newly eclosed slo flies but not in $S h$ flies. $I_{\mathrm{C}}$ is known to be the last of the ion currents to appear in DLMs and is not fully mature in newly eclosed adults (Salkoff, $1983 \mathrm{~b}, 1985)$. At the time it replaces $I_{\mathrm{A}}$ as the repolarizing current, $I_{C}$ is undergoing a marked increase in amplitude (Salkoff, 1985).

The reason why $I_{\mathrm{A}}$ is insufficient to bring about rapid repolarization of DLM spikes in mature adults is not yet understood. The results suggest some type of age-dependent change in the relative strengths of $I_{\mathrm{A}}$ and the inward $\mathrm{Ca}^{2+}$ current. For example, $I_{\mathrm{A}}$ may decrease in amplitude or it may remain constant while the DLM membrane area or $\mathrm{Ca}^{2+}$ current increase. The $\mathrm{Ca}^{2+}$ current first becomes evident only around the time of eclosion (Salkoff, 1985) and may subsequently increase in amplitude. The possible biological significance of this transition of DLM spike repolarization from a mechanism that is $I_{\mathrm{A}}$ dependent to one that is $I_{\mathrm{C}}$ dependent remains to be examined.

Although the specific defects of the $S h$ and slo mutations permit the roles of $I_{\mathrm{A}}$ and $I_{\mathrm{C}}$ in DLM activity to be dissected with some precision, the role of $I_{\mathrm{K}}$ is less clear owing to the lack of any genetic or pharmacological means of blocking this current specifically. Nonetheless, our results indicate that in the absence of $I_{C}$, repolarization of the DLM spike is accomplished eventually by $I_{\mathrm{K}}$. When $I_{\mathrm{K}}$ is eliminated along with $I_{C}$, spike duration can be as long as several seconds. We have yet to determine the physiological consequences of eliminating $I_{\mathrm{K}}$ from the DLMs while leaving $I_{c}$ functionally intact.

When all $\mathrm{K}^{+}$currents have been eliminated, $\mathrm{Ca}^{2+}$ current inactivation may itself terminate the prolonged muscle spike. The difference we observed in duration and amplitude of the DI.M response in $\mathrm{Ba}^{2+}$ - versus TEA-containing saline, despite the fact that both treatments greatly reduce or eliminate all outward currents, may then be attributable to the additional block of inward current inactivation in $\mathrm{Ba}^{2+}$-containing saline. The data suggest that inactivation of $\mathrm{Ca}^{2+}$ current may also be responsible for the long interspike interval observed in slo DLMs. When all $\mathrm{K}^{+}$currents are present or when only $I_{\mathrm{A}}$ is missing, the interval between spikes in these experiments was about 20 msec. In the absence of $I_{\mathrm{C}}$, this interval increased to more than $40 \mathrm{msec}$. Because $\mathrm{Ca}^{2+}$ current inactivation in insect muscle is strongly dependent on internal free $\mathrm{Ca}^{2+}$ (Ashcroft and Stanfield, 1981), it may be that the prolonged $\mathrm{Ca}^{2+}$ influx in slo DLMs transiently increases the cytosolic $\mathrm{Ca}^{2+}$ leading to more complete inactivation of $\mathrm{Ca}^{2+}$ current. When $\mathrm{Ca}^{2+}$ influx was further incrcased in TEA-treated DLMs, there was an apparent spike refractory period of a second or more between the very prolonged responses (data not shown).

Without the slo mutation, it would have been very difficult to demonstrate directly the roles of $I_{\mathrm{C}}$ in DLM electrical activity for lack of a method to eliminate this current specifically. Charybdotoxin, a peptide toxin from scorpion venom, preferentially blocks $I_{C}$ channels in various systems (Hermann, 1985; Miller et al., 1985; Obaid et al., 1985), including Drosophila DLMs (Elkins et al., 1986). However, at doses required to block $I_{\mathrm{C}}$ as completely as in the slo mutant, the toxin also reduced the $\mathrm{Ca}^{2+}$ inward current (T. Elkins, unpublished observations). $I_{\mathrm{C}}$ is likely to have important functional roles outside the DLMs. For example, a $\mathrm{Ca}^{2+}$-dependent $\mathrm{K}^{+}$current is thought to play a role in the repolarization of the presynaptic terminal of the larval neuromuscular junction (Jan et al., 1977; Ganetzky and Wu, 1982). In addition, a $\mathrm{Ca}^{2+}$-dependent $\mathrm{K}^{+}$current has been implicated in the ionic mechanism underlying associative conditioning in another invertebrate, Hermissenda (Grover and Farley, 1985). Thus, the slo mutation may prove equally useful in the analysis of the physiological roles of $\mathrm{Ca}^{2+}$-dependent $\mathrm{K}^{+}$ currents in neuronal activity and in more complex neural processes.

\section{References}

Adams, P. R., A. Constanti, D. A. Brown, and R. B. Clark (1982) Intracellular $\mathrm{Ca}^{2+}$ activates a fast voltage-sensitive $\mathrm{K}^{+}$current in vertebrate sympathetic neurones. Nature 296: 746-749.

Ashcroft, F. M., and P. R. Stanfield (1981) Calcium dependence of the inactivation of calcium currents in skeletal muscle fibers of an insect. Science 213: 224-226.

Boettinger, E. C. (1951) Stimulation of the flight of the fly. Anat. Rec. 111: 443

Byrne, J. H. (1980) Quantitative aspects of ionic conductance mechanisms contributing to firing pattern of motor cells mediating inking behavior in Aplysia californica. J. Neurophys. 43: 651-668.

Conner, J. A., and C. F. Stevens (1971a) Voltage clamp studies of a transient outward current in gastropod neural somata. J. Physiol. (Lond.) 213: 21-30.

Conner, J. A., and C. F. Stevens (1971b) Prediction of repetitive firing behavior from voltage clamp data on an isolated neurone somata. J. Physiol. (Lond.) 213: 31-53.

Eaton, D. C., and M. B. Brodwick (1980) Effects of barium on the potassium conductance of squid axon. J. Gen. Physiol. 75: 727-750.

Elkins, T. T., B. Ganetzky, and C.-F. Wu (1984) A Drosophila mutant with a defect in a $\mathrm{Ca}^{2+}$-dependent outward current. Soc. Neurosci. Abstr. 10: 1090.

Elkins, T., B. Ganetzky, and C.-F. Wu (1986) A gene affecting a calcium-dependent potassium current in Drosophila. Proc. Natl. Acad. Sci. USA 83: 8415-8419.

Fatt, P., and B. Katz (1953) The electrical properties of crustacean muscle fibers. J. Physiol. (Lond.) 120: 171-204.

Ganetzky, B., and C.-F. Wu (1982) Drosophila mutants with opposing effects on nerve excitability: Genetic and spatial interactions in repetitive firing. J. Neurosphysiol. 47: 501-514.

Ganetzky, B., and C.-F. Wu (1986) Neurogenetics of membrane excitability in Drosophila. Annu. Rev. Genet. 20: 13-44.

Getting, P. A. (1983) Mechanisms of pattern generation underlying swimming in Tritonia. III. Intrinsic and synaptic mechanisms for delayed excitation. J. Neurophys. 49: 1036-1050.

Grover, L., and J. Farley (1985) $\mathrm{I}_{\mathrm{K} . \mathrm{C}_{\mathrm{a}}}$ but not $\mathrm{I}_{\mathrm{A}}$ is reduced during in vitro conditioning of Hermissenda type B cells. Soc. Neurosci. Abstr. 11: 788.

Harcombe, E. S., and R. J. Wyman (1978) The cyclically repetitive firing sequences of identified Drosophila flight motoneurons. J. Comp. Physiol. 123: 271-279.

Hermann, A. (1985) Charybdotoxin specifically blocks Ca-activated K conductance of Aplysia neurons. Soc. Neurosci. Abstr. 11: 789.

Hodgkin, A. L., and A. F. Huxley (1952) A quantitative description of membrane current and its application to conduction and excitation in nerve. J. Physiol. (Lond.) 117: 500-544. 
Hoyle, G. (1967) Specificity of muscle. In Invertebrate Nervous Systems: Their Significance for Mammalian Physiology, C. A. G. Wiersma, ed., pp. 151-167, University of Chicago Press, Chicago, IL.

Ikeda, K., and W. D. Kaplan (1974) Neurophysiological genetics in Drosophila melanogaster. Am. Zoologist 14: 1055-1066.

Jan, Y. N., L. Y. Jan, and M. J. Dennis (1977) Two mutations of synaptic transmission in Drosophila. Proc. R. Soc. London [Biol.] 198: 87-108.

King, D. G., and R. J. Wyman (1980) Anatomy of the giant fibre pathway in Drosophila. I. Three thoracic components of the pathway. J. Neurocytol. 9: 753-770.

Koenig, J. H., and K. Ikeda (1980) Flight pattern induced by temperature in a single-gene mutant of Drosophila melanogaster. J. Neurobiol. 11: 509-517.

Kripke, B. R., and T. E. Ogden (1974) A technique for bevelling fine micropipettes. Electroencephalogr. Clin. Neurophysiol. 36: 323-326.

MacDermott, A. B., and F. F. Weight (1982) Action potential repolarization may involve a transient, $\mathrm{Ca}^{2+}$-sensitive outward current in a vertebrate neuron. Nature $300: 185-188$.

Miller, A. (1965) The internal anatomy and histology of the imago of Drosophila melanogaster. In Biology of Drosophila, M. Demerec, ed., pp. 420-534, Hafner, New York.

Miller, C., E. Moczydlowski, R. Latorre, and M. Phillips (1985) Charybdotoxin, a protein inhibitor of single $\mathrm{Ca}^{2+}$-activated $\mathrm{K}^{+}$channels from mammalian skeletal muscle. Nature 313: 316-318.

Miller, R. J. (1987) Multiple calcium channels and neuronal function. Science 235: 46-52.

Obaid, A. L., D. Langer, and B. M. Salzberg (1985) Charybdotoxin (CTX) selectively blocks a calcium-mediated potassium conductance that contributes to the action potential recorded optically from nerve terminals of the frog neurohypophysis. Soc. Neurosci. Abstr. 11: 789.

Rogawski, M. A., B. Dufy, and J. L. Barker (1985) The calcium- and voltage-dependent $\mathrm{K}^{+}$channel of clonal anterior pituitary cells: Pharmacological manipulation and role in action potential repolarization. Soc. Neurosci. Abstr. 11: 797.
Salkoff, L. (1983a) Drosophila mutants reveal two components of fast outward current. Nature 302: 249-251.

Salkoff, L. (1983b) Genetic and voltage clamp analysis of a Drosophila potassium channel. Cold Spring Harbor Symp. Quant. Biol. 48: 221231.

Salkoff, L. (1985) Development of ion channels in the muscles of Drosophila. J. Physiol. (Paris) 80: 275-282.

Salkoff, L. B., and M. A. Tanouye (1986) Genetics of ion channels. Physiol. Rev. 66(2): 302-329.

Salkoff, L., and R. Wyman (1980) Facilitation of membrane excitability in Drosophila. Proc. Natl. Acad. Sci. USA 77: 6216-6220.

Salkoff, L., and R. Wyman (1981) Genetic modification of potassium channels in Drosophila Shaker mutants. Nature 293: 228-230.

Salkoff, L., and R. Wyman (1983) Ionic currents in Drosophila. J. Physiol. (Lond.) 337: 687-709.

Segal, M., M. A. Rogawski, and J. L. Barker (1984). A transient potassium conductance regulates the excitability of cultured hippocampal and spinal neurons. J. Neurosci. 4: 604-609.

Shimahara, T. (1983) Presynaptic modulation of transmitter release by the outward potassium current in Aplysia. Brain Res. 263: 51-56.

Tanouye, M. A., C. A. Kamb, L. E. Iverson, and L. Salkoff (1986) Genetics and molecular biology of ionic channels in Drosophila. Annu. Rev. Neurosci. 9: 255-276.

Thompson, S. H. (1977) Three pharmacologically distinct potassium channels in molluscan neurones. J. Physiol. (Lond.) 265: 465-488.

Wei, A., and L. Salkoff (1986) Occult Drosophila calcium channels and twinning of calcium and voltage-activated potassium channels. Science 233: 780-782.

Wu, C.-F., and F. Haugland (1985) Altered potassium conductances in larval muscle fibers of Shaker mutants of Drosophila. J. Neurosci. 5: 2626-2640.

Wu, C.-F., B. Ganetzky, F. N. Haugland, and A.-X. Liu (1983) Potassium currents in Drosophila: Different components affected by mutations in two genes. Science 220: 1076-1078. 